\title{
Clinical efficacy evaluation of treatment of different degrees of retinal vein occlusion with ranibizumab combined with an argon ion laser
}

\author{
DINGDING WANG, XIAOYI WANG, KUNFANG WU, JUANJUAN WANG, GUIHUA XU and ZILIN CHEN \\ Ophthalmological Center of Huizhou Municipal Central Hospital, Huizhou, Guangdong 516000, P.R. China
}

Received October 21, 2017; Accepted November 21, 2018

DOI: $10.3892 /$ etm.2018.7125

\begin{abstract}
The aim of this study was to evaluate the clinical efficacy of an intravitreal injection of ranibizumab combined with argon ion laser photocoagulation therapy in the treatment of different degrees of central retinal vein occlusion (CRVO). A total of 112 CRVO patients including 25 cases of trunk occlusion, 50 cases of branch occlusion and 37 cases of hemiretinal vein-occlusion were enrolled in this study. Patients were treated with an intravitreal injection of $0.5 \mathrm{mg}$ ranibizumab, followed by argon ion laser photocoagulation therapy after 7 days. Patients were followed up for 6 months and the best corrected visual acuity (BCVA), central retinal thickness (CRT), macular edema, and surgical complications were compared. Compared with the control treated with $0.5 \mathrm{mg}$ ranibizumab, the BCVA and macular edema improved while CRT was significantly reduced in all groups treated with $0.5 \mathrm{mg}$ ranibizumab combined with the argon ion laser. Furthermore, no obvious complications were observed in these groups and the effects of ranibizumab combined with argon ion laser photocoagulation on branch occlusion group were the best. Intravitreal injection of ranibizumab combined with argon ion laser photocoagulation therapy has better safety and effectiveness in the treatment of different degrees of CRVO. The trial registration number is 2015-318 and date of registration is $12 / 10 / 2015$.
\end{abstract}

\section{Introduction}

Retinal vein occlusion (RVO) has been reported to be the second most common retinal vascular disease following diabetic retinopathy (1), which commonly leads to vision loss in the elderly population and is frequently associated with arteriosclerotic diseases and glaucoma. It is traditionally divided

Correspondence to: Dr Zilin Chen, Ophthalmological Center of Huizhou Municipal Central Hospital, 41 Eling North Road, Huizhou, Guangdong 516000, P.R. China

E-mail: jing8847353tuiyu@163.com

Key words: ranibizumab, argon ion laser, central retinal vein occlusion, treatment into central retinal vein occlusion (CRVO) and branch retinal vein occlusion (BRVO) (2). The present study focused on CRVO that has been reported widely to cause blinding fundus lesions mainly characterized by retinal hemorrhage, exudation and cystoid macular edema. The occurrence of CRVO is associated with age, which is mostly accompanied with chronic systemic diseases, including hypertension, diabetes and arteriosclerosis (3). According to fundus fluorescein angiography (FFA), CRVO can be divided into ischemic and non-ischemic types. The non-ischemic type is common in the clinic and occurs in the early stage of disease, so the visual prognosis is relatively good. Occlusion may occur in the central trunk, branch or hemiretinal vein (hemi) and its duration is divided into $\leq 1$ month, 1-3 months and $>3$ months.

The important risk factors for CRVO in patients older than 50 years mainly include systemic hypertension and vascular disease. In addition, diabetes mellitus and hyperlipidemia, African-descent ethinicity, male gender, peripheral artery disease, stroke, hypercoagulable state, ocular hypertension and primary open-angle glaucoma also add to the prevalance of CRVO (4). On the other hand, hyperlipidemia has been reported to be the predominant medical condition associated with CRVO in young patients (5). All these pathological conditions utlimately result in systemic diseases leading to inflammatory alterations in the blood vessels of the retina, which in turn cause occlusion of the central retinal vein (6).

The clinical treatment used widely for CRVO is the combination of intravitreal injection of ranibizumab with argon ion laser photocoagulation (7). Combination therapy has already demonstrated higher safety and better efficacy, in comparison with the single therapy $(8,9)$. However, there is paucity of information with regard to the efficacy of this combination at variable degrees of CRVO. Therefore, in the present study, the clinical efficacy of ranibizumab combined with argon ion laser photocoagulation therapy on CRVO in different degrees was analyzed.

\section{Materials and methods}

Study subjects. A total of 112 patients continuously diagnosed as CRVO in the Huizhou Municipal Central Hospital (Huizhou, China) from June 2014 to October 2016 were selected. Written informed consent was provided by the patients. Inclusion criteria: i) Patients with monocular lesions 
Table I. Baseline data of patients in the three groups.

\begin{tabular}{lccccc}
\hline Group & $\begin{array}{c}\text { Trunk occlusion } \\
(\mathrm{n}=25)\end{array}$ & $\begin{array}{c}\text { Branch occlusion } \\
(\mathrm{n}=50)\end{array}$ & $\begin{array}{c}\text { Hemi-occlusion } \\
(\mathrm{n}=37)\end{array}$ & $\mathrm{F} / \chi^{2}$ value & P-value \\
\hline Male/Female & $14 / 11$ & $22 / 28$ & $19 / 18$ & 1.072 & 0.585 \\
Age (years) & $52.6 \pm 10.7$ & $53.3 \pm 11.2$ & $53.8 \pm 13.2$ & 0.562 & 0.649 \\
Course of disease (months) & $1.8 \pm 0.5$ & $1.9 \pm 0.7$ & $1.8 \pm 0.6$ & 0.253 & 0.864 \\
CRT $(\mu \mathrm{m})$ & $635 \pm 50$ & $642 \pm 55$ & $647 \pm 62$ & 0.642 & 0.596 \\
BCVA & $0.24 \pm 0.08$ & $0.25 \pm 0.09$ & $0.23 \pm 0.07$ & 0.153 & 0.863 \\
Intraocular pressure (mmHg) & $20.5 \pm 3.6$ & $19.6 \pm 3.3$ & $21.2 \pm 3.8$ & 0.345 & 0.769 \\
Hypertension [n (\%)] & $6(24.0)$ & $10(20.0)$ & $7(18.9)$ & 0.252 & 0.882 \\
Diabetes [n (\%)] & $4(16.0)$ & $6(12.0)$ & $4(10.8)$ & 0.372 & 0.830 \\
\hline
\end{tabular}

CRT, central retinal thickness; BCVA, best corrected visual acuity.

and the best corrected visual acuity (BCVA) $<0.3$; ii) patients with optic disc edema, blurred edges, cystoid macular edema, hemorrhage, smaller arterial diameter, venous tortuous dilatation, retinal edema and flame bleeding in fundus demonstrated by fundus photography, and with prolonged retinal circulation time, aneurysmal dilatation of blood capillaries, fluorescein leakage, large non-perfusion area, stained venous wall and diffuse fluorescein leakage of macula lutea demonstrated by FFA, and with retinal thickening, edema and hemorrhage demonstrated by optical coherence tomography (OCT) and damaged retinal pigment epithelium; iii) patients who did not receive the intravitreal injection, laser photocoagulation and drug therapy promoting circulation and removing stasis; iv) patients with clinical data and informed consent right obtained. Exclusion criteria: i) Patients with glaucoma, cataract, proliferative vitreoretinopathy, macular ischemia, diabetic retinopathy, age-associated macular degeneration, eye traumas or other eye diseases; ii) patients with severe hypertension, diabetes, atherosclerosis or cardiovascular and cerebrovascular diseases; iii) patients who participated in other studies at the same time and quit the study voluntarily. The study was approved by the Ethics Committee of Huizhou Municipal Central Hospital. Patient characteristics are presented in Table I.

Research methods. The patients were divided into the following groups: The trunk occlusion group (12 patients for ranibizumab treatment, 13 patients for ranibizumab+argon ion laser treatment), the branch occlusion group (25 patients for ranibizumab treatment, 25 patients for ranibizumab+argon ion laser treatment) and the hemi-occlusion group (18 patients for ranibizumab treatment, 19 patients for ranibizumab+argon ion laser treatment). All patients were intravitreally injected with $0.5 \mathrm{mg}$ ranibizumab (Lucentis; Novartis International AG, Basel, Switzerland), followed by argon ion laser photocoagulation after 7 days. The specific steps were as follows: Prior to operation, levofloxacin hydrochloride eye drops were dropped into the eyes for 3 days continuously (4 times per day); following conventional disinfection and topical anesthesia with $50 \mathrm{~g} / 1$ oxybuprocaine hydrochloride, povidone-iodine eye drops were used for disinfecting eyeballs, and after $90 \mathrm{sec}$, normal saline was used to wash the cornea and bulbar conjunctival sac;
$1 \mathrm{ml}$ empty needle was used to extract $0.05 \mathrm{ml}(0.5 \mathrm{mg})$ ranibizumab and inject it into the vitreous body at $4 \mathrm{~mm}$ behind the inferotemporal corneal limbus, and change of the intraocular pressure was observed. After the needle was removed, the sterile wet cotton swab was used to press the wound for 1-2 min, followed by wound painting using levofloxacin oculentum and dressing of affected eye. Patients treated with only $0.5 \mathrm{mg}$ ranibizumab were used as the controls.

The solid laser therapeutic instrument (Iridex, Mountain View, CA, USA) with the frequency multiplication of $532 \mathrm{~nm}$ was used for grid photocoagulation in the macular region. Parameters included spot diameter in $100 \mu \mathrm{m}$, energy at 100-140 mW, exposure time at $0.1 \mathrm{msec}$, spot reaction at I level, distance away from macula central fovea with 1-2 optic disc diameters, ring photocoagulation outward and photocoagulation range from the upper, and lower vascular arcades to the bitamporal junction. The optic disc maculary fasciculi were retained. According to the FFA results of patients, if necessary, the retinal non-perfusion area and local photocoagulation of novel vessels were combined. Photocoagulation parameters of retinal non-perfusion area: Spot diameter in $200 \mu \mathrm{m}$, energy at $180-260 \mathrm{~mW}$, exposure time at $0.2 \mathrm{msec}$ and spot reaction at II level. The laser should avoid the retinal hemorrhage or thick area and the photocoagulation should be 1 optic disc diameter away from the non-perfusion area or peripheral new vessels.

Observational indexes. BCVA, CRT, macular edema and surgical complications at 1 month, 3 months and 6 months following operation among all groups were compared. BCVA was detected using the international standard visual acuity chart (converted into Log MAR visual acuity). CRT was measured according to OCT and the decrease of CRT $>100 \mu \mathrm{m}$ compared with the results detected previously was regarded as the recession.

Statistical analysis. Statistical Product and Service Solutions (SPSS) 20.0 software (IBM, Corps., Armonk, NY, USA) was used for statistical analysis. Measurement data were presented as mean \pm standard deviation. One-way analysis of variance (ANOVA) was used for the comparison among the groups. Least significance difference-t test was used for pairwise comparison. Repeated measurement ANOVA was used for 


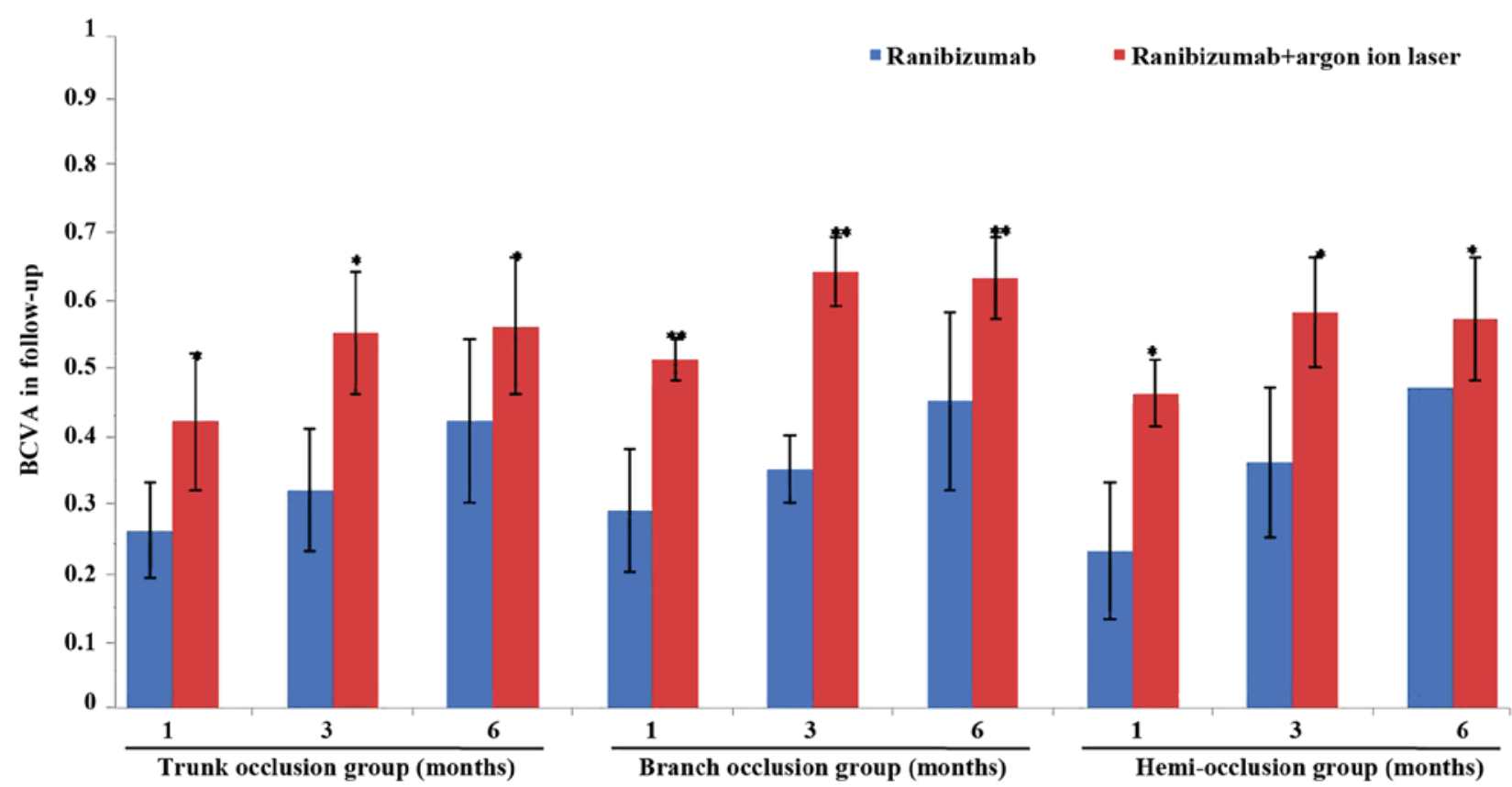

Figure 1. Comparison of BCVA in follow-up. In 1, 3 and 6 months of follow-up, BCVA was evaluated in trunk occlusion group, branch occlusion group, hemi-occlusion group treated with ranibizumab or ranibizumab combined with argon ion laser. " $\mathrm{P}<0.05$ and ${ }^{* *} \mathrm{P}<0.01$ vs. the control. BCVA, best corrected visual acuity.

Table II. Comparison of best corrected visual acuity in follow-up.

\begin{tabular}{|c|c|c|c|c|c|c|}
\hline \multirow[b]{2}{*}{ Items } & \multicolumn{2}{|c|}{ Trunk occlusion group } & \multicolumn{2}{|c|}{ Branch occlusion group } & \multicolumn{2}{|c|}{ Hemi-occlusion group } \\
\hline & $\begin{array}{c}\text { Ranibizumab } \\
\quad(\mathrm{n}=17)\end{array}$ & $\begin{array}{l}\text { Ranibizumab + argon } \\
\quad \text { ion laser }(n=18)\end{array}$ & $\begin{array}{l}\text { Ranibizumab } \\
\qquad(\mathrm{n}=25)\end{array}$ & $\begin{array}{l}\text { Ranibizumab }+ \text { argon } \\
\text { ion laser }(\mathrm{n}=25)\end{array}$ & $\begin{array}{l}\text { Ranibizumab } \\
\qquad(\mathrm{n}=18)\end{array}$ & $\begin{array}{l}\text { Ranibizumab }+ \text { argon } \\
\text { ion laser }(n=19)\end{array}$ \\
\hline 1 month & $0.26 \pm 0.07$ & $0.42 \pm 0.16^{\mathrm{a}}$ & $0.29 \pm 0.09$ & $0.51 \pm 0.23^{b}$ & $0.23 \pm 0.10$ & $0.46 \pm 0.15^{\mathrm{a}}$ \\
\hline 3 months & $0.32 \pm 0.09$ & $0.55 \pm 0.19^{\mathrm{a}}$ & $0.35 \pm 0.15$ & $0.64 \pm 0.25^{\mathrm{b}}$ & $0.36 \pm 0.11$ & $0.58 \pm 0.18^{\mathrm{a}}$ \\
\hline 6 months & $0.42 \pm 0.12$ & $0.56 \pm 0.21^{\mathrm{a}}$ & $0.45 \pm 0.13$ & $0.63 \pm 0.26^{\mathrm{b}}$ & $0.47 \pm 0.06$ & $0.57 \pm 0.19^{a}$ \\
\hline
\end{tabular}

${ }^{\mathrm{a}} \mathrm{P}<0.05$ and ${ }^{\mathrm{b}} \mathrm{P}<0.05$ vs. the control.

value comparisons in different time of follow-up. Enumeration data were presented as case or percentage (\%) and Chi-square test was used for intergroup comparison. $\mathrm{P}<0.05$ was considered to indicate a statistically significant difference.

\section{Results}

In the present results revealed that there were 25 cases of trunk occlusion, 50 cases of branch occlusion and 37 cases of hemiocclusion. The baseline data of patients in the three groups presented that there was no difference in sex, age, course of disease, CRT, BCVA, intraocular pressure, hypertension and diabetes between three groups $(\mathrm{P}>0.05$, Table I).

As shown in Fig. 1, compared with the controls treated with ranibizumab alone, after patients with the trunk occlusion, the branch occlusion or the hemi-occlusion were treated with ranibizumab combined with argon ion laser, the BCVA of all groups improved significantly following the operation and the branch occlusion group exhibited the best results $(\mathrm{P}<0.05$; Table II and Fig. 1). However, the significant reduction in the
CRT following combination therapy was observed in all groups and the best effects were noted in the branch occlusion group $(\mathrm{P}<0.05$; Table III and Fig. 2). Furthermore, in the 6-month follow-up, the remission rate of macular edema of each group gradually decreased and the effect in branch occlusion group was the best (Table IV and Fig. 3). In addition, no severe surgical complications like endophthalmitis, retinal detachment and intraocular hypertension, were noticed in all three groups (data not shown).

\section{Discussion}

Therapeutic options for CRVO have been demonstrated during the last 5 years, which include intravitreally delivered corticosteroids and intravitreal injections of agents against vascular endothelial growth factor (VEGF) $(10,11)$. It was demonstrated in an animal model that obstructed cerebral venous drainage can lead to increased fundus arteriovenous pressure, capillary non-perfusion, tissue ischemia, hypoxia and inflammatory response, and promote the increased release of VEGF and 
Table III. Comparison of central retinal thickness in follow-up $(\mu \mathrm{m})$.

\begin{tabular}{|c|c|c|c|c|c|c|}
\hline \multirow[b]{2}{*}{ Items } & \multicolumn{2}{|c|}{ Trunk occlusion group } & \multicolumn{2}{|c|}{ Branch occlusion group } & \multicolumn{2}{|c|}{ Hemi-occlusion group } \\
\hline & $\begin{array}{l}\text { Ranibizumab } \\
\qquad(\mathrm{n}=17)\end{array}$ & $\begin{array}{l}\text { Ranibizumab }+ \text { argon } \\
\text { ion laser }(n=18)\end{array}$ & $\begin{array}{l}\text { Ranibizumab } \\
\qquad(\mathrm{n}=25)\end{array}$ & $\begin{array}{l}\text { Ranibizumab }+ \text { argon } \\
\text { ion laser }(n=25)\end{array}$ & $\begin{array}{l}\text { Ranibizumab } \\
\qquad(\mathrm{n}=18)\end{array}$ & $\begin{array}{l}\text { Ranibizumab + argon } \\
\text { ion laser }(n=19)\end{array}$ \\
\hline 1 month & $973 \pm 68$ & $608 \pm 45^{\mathrm{a}}$ & $928 \pm 102$ & $570 \pm 45^{b}$ & $1021 \pm 89$ & $585 \pm 52^{a}$ \\
\hline 3 months & $816 \pm 27$ & $570 \pm 50^{\mathrm{b}}$ & $747 \pm 34$ & $530 \pm 50^{\mathrm{b}}$ & $828 \pm 51$ & $550 \pm 46^{\mathrm{b}}$ \\
\hline 6 months & $823 \pm 12$ & $565 \pm 48^{a}$ & $769 \pm 52$ & $535 \pm 46^{b}$ & $832 \pm 77$ & $545 \pm 43^{a}$ \\
\hline
\end{tabular}

${ }^{\mathrm{a}} \mathrm{P}<0.05$ and ${ }^{\mathrm{b}} \mathrm{P}<0.05$ vs. the control.

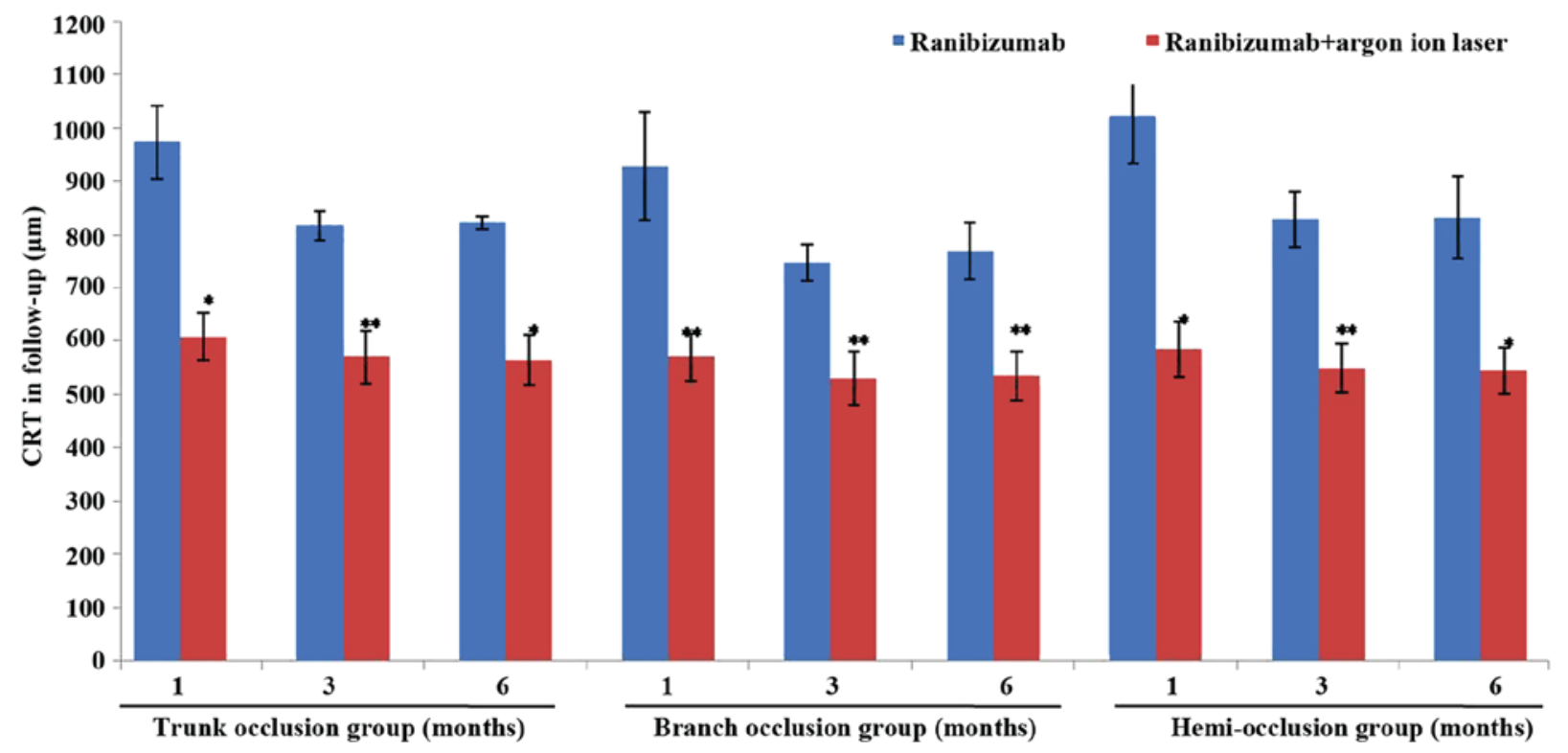

Figure 2. Comparison of CRT in follow-up $(\mu \mathrm{m})$. In 1, 3 and 6 months of follow-up, CRT was evaluated in trunk occlusion group, branch occlusion group, hemiocclusion group treated with ranibizumab or ranibizumab combined with argon ion laser. ${ }^{*} \mathrm{P}<0.05$ and ${ }^{* * *} \mathrm{P}<0.01$ vs. the control. CRT, central retinal thickness.

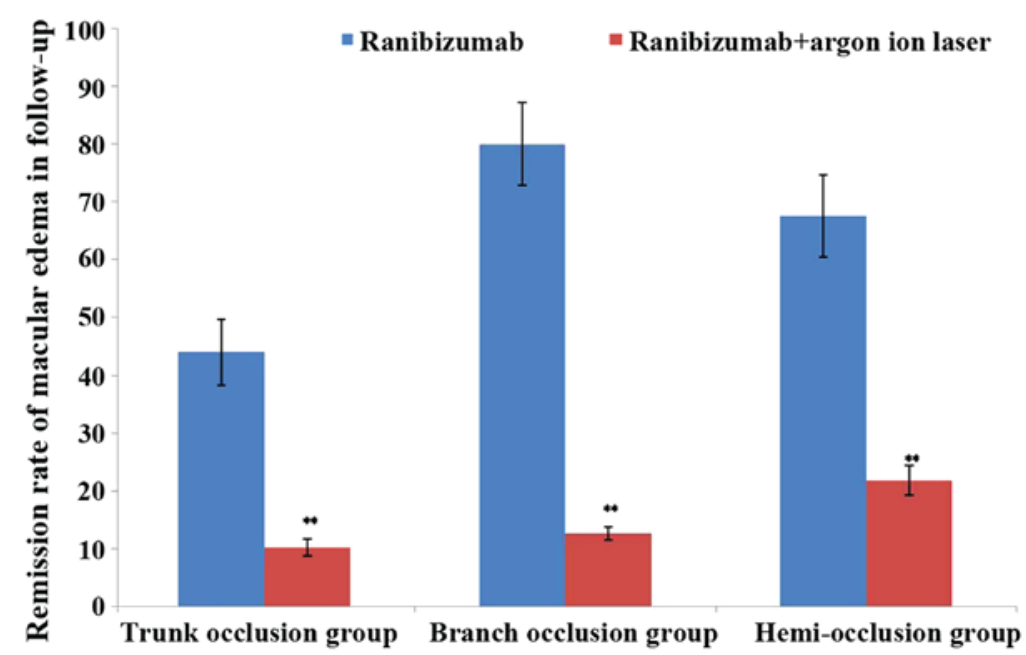

Figure 3. Comparison of the remission rate of macular edema in follow-up (\%). In 6 months of follow-up, the remission rate of macular edema was evaluated in trunk occlusion group, branch occlusion group, hemi-occlusion group treated with ranibizumab or ranibizumab combined with argon ion laser. ${ }^{* *} \mathrm{P}<0.01$ vs. the control.

induce neovascularization. Furthermore, the structure and function of the novel vessels is imperfect, especially with respect to the increased permeability, easy bleeding, leakage and edema, aggravating the retinal and macular pathological 
Table IV. Comparison of remission rate of macular edema in follow-up (\%).

\begin{tabular}{|c|c|c|c|c|c|c|}
\hline \multirow[b]{2}{*}{ Items } & \multicolumn{2}{|c|}{ Trunk occlusion group } & \multicolumn{2}{|c|}{ Branch occlusion group } & \multicolumn{2}{|c|}{ Hemi-occlusion group } \\
\hline & $\begin{array}{l}\text { Ranibizumab } \\
\qquad(\mathrm{n}=17)\end{array}$ & $\begin{array}{l}\text { Ranibizumab }+ \text { argon } \\
\text { ion laser }(n=18)\end{array}$ & $\begin{array}{l}\text { Ranibizumab } \\
\qquad(\mathrm{n}=25)\end{array}$ & $\begin{array}{l}\text { Ranibizumab }+ \text { argon } \\
\text { ion laser }(n=25)\end{array}$ & $\begin{array}{l}\text { Ranibizumab } \\
\qquad(\mathrm{n}=18)\end{array}$ & $\begin{array}{l}\text { Ranibizumab + argon } \\
\text { ion laser }(n=19)\end{array}$ \\
\hline 6 months & $44.0 \pm 5.7$ & $10.2 \pm 1.5^{\mathrm{b}}$ & $80.0 \pm 7.22$ & $12.6 \pm 1.2^{\mathrm{b}}$ & $67.6 \pm 7.10$ & $21.8 \pm 2.52^{b}$ \\
\hline
\end{tabular}

${ }^{\mathrm{b}} \mathrm{P}<0.05$ vs. the control.

changes $(12,13)$. In the present study, to avoid bias of results, all the patients were randomly chosen and their situations were different. If the group size was made the same on purpose it may have lead to a much bigger bias of results. A literature search was performed and there are also a number of studies including patient groups of different sizes. Furthermore, the patients were divided into the following groups: The trunk occlusion group (12 patients for ranibizumab treatment and 13 patients for ranibizumab+argon ion laser treatment), the branch occlusion group ( 25 patients for ranibizumab treatment and 25 patients for ranibizumab+argon ion laser treatment) and the hemi-occlusion group (18 patients for ranibizumab treatment and 19 patients for ranibizumab+argon ion laser treatment). Then, the effects of intravitreal injection of ranibizumab in combination with argon ion laser therapy were evaluated in the treatment of CRVO in different degrees and present the safety, and efficacy of this treatment approaches for CRVO in different degrees.

Ranibizumab is a novel anti-VEGF agent with humanized monoclonal antibody fragment targeting all isoforms of VEGF, which is frequently applied in eyes diseases. For instance, it has been reported that ranibizumab used in the specific resistance to VEGF can inhibit the production of novel blood vessels to a greater extent, thereby reducing the retinal exudation and bleeding $(14,15)$. Studies have confirmed that macular edema is caused by the damaged blood retinal barrier (internal barrier) and pigment epithelial barrier (external barrier). CRVO can lead to internal and external barrier dysfunction at the same time, and release a variety of endogenous cytokines, among which VEGF is the most studied $(16,17)$. At present, the clinical treatment of CRVO-associated persistent nonischemic macular edema with laser photocoagulation is still the standard method (18), which reduces edema to a certain extent, but the efficacy on complex edema is poor with severe side effects (19) and limited vision improvement $(20,21)$. Previous findings demonstrated that intravitreal injection of ranibizumab or conbercept combined with laser therapy is an effective therapeutic option in Coats' disease (22). Another research team confirmed that ranibizumab $0.5 \mathrm{mg}$ can treat patients with BRVO. Addition of laser treatment did not lead to better functional outcomes or a reduced treatment requirement (23). In the present study, intravitreal injection of ranibizumab combined with argon ion laser therapy is demonstrated to be a good method for CRVO treatment.

The results of the present study suggest that BCVA of the three groups is increased, CRT is reduced, macular edema is improved and the best status can be obtained at 3 months following ranibizumab combined with argon ion laser therapy. No obvious complications occur and the effects in branch occlusion group are the best. Therefore, it is hypothesized that the intravitreal injection of ranibizumab combined with argon ion laser photocoagulation has better safety and effectiveness in the treatment of different degrees of CRVO. The impairment of vision from trunk occlusion or hemi-occlusion is more serious than in branch occlusion and CRT is increased significantly, accompanied by severe local edema, bleeding, and leakage $(24,25)$; trunk occlusion or hemi-occlusion frequently involves the distal branch vessels; although there may be more target vessels in branch occlusion, pathological changes, including ischemia and inflammation, are mild, and it has a better response to the ranibizumab combined with laser photocoagulation therapy $(26,27)$.

In conclusion, the present study suggests that the clinical application of intravitreal injection of ranibizumab combined with argon ion laser photocoagulation is suitable for the treatment of CRVO in different degrees, providing an important reference for the early screening of population with the optimal efficacy. This information can be used to help patients achieving good visual recovery. However, the specific mechanism remains to be further studied. The shortcomings in this study are the small sample size, lack of treatment randomization and disunited criteria of different occlusion degrees.

\section{Acknowledgements}

Not applicable.

Funding

No funding was received.

\section{Availability of data and materials}

The datasets used during the current study are available from the corresponding author on reasonable request.

\section{Authors' contributions}

DW designed the study and wrote the manuscript. XW and KW collected the clinical data, JW and GX conducted the statistical analysis. As the corresponding author, ZC contributed to the conception and design of the study, approved the final manuscript as submitted, and revised the manuscript. All authors approved this edited version of article to be published. 


\section{Ethics approval and consent to participate}

Written informed consent was provided by the patients. The study was approved by the Ethics Committee of Huizhou Municipal Central Hospital (Huizhou, China).

\section{Patient consent for publication}

Not applicable.

\section{Competing interests}

All authors declared no competing interests.

\section{References}

1. Wittström E: Central retinal vein occlusion in younger Swedish adults: Case reports and review of the literature. Open Ophthalmol J 11: 89-102, 2017.

2. Yau JW, Lee P, Wong TY, Best J and Jenkins A: Retinal vein occlusion: An approach to diagnosis, systemic risk factors and management. Intern Med J 38: 904-910, 2008.

3. Nroev VV: Modern aspects of diabetic retinopathy and diabetic macularoedema treatment. Vestn Ross Akad Med Nauk 1: 61-65, 2012.

4. Kolar P: Risk factors for central and branch retinal vein occlusion: A meta-analysis of published clinical data. J Ophthalmol 2014: 724780, 2014.

5. Kuo JZ, Lai CC, Ong FS, Shih CP, Yeung L, Chen TL, Chen KJ and $\mathrm{Wu}$ WC: Central retinal vein occlusion in a young Chinese population: Risk factors and associated morbidity and mortality. Retina 30: 479-484, 2010.

6. Priluck IA, Robertson DM and Hollenhorst RW: Long-term follow-up of occlusion of the central retinal vein in young adults. Am J Ophthalmol 90: 190-202, 1980.

7. Spaide RF, Chang LK, Klancnik JM, Yannuzzi LA, Sorenson J, Slakter JS, Freund KB and Klein R: Prospective study of intravitreal ranibizumab as a treatment for decreased visual acuity secondary to central retinal vein occlusion. Am J Ophthalmol 147: 298-306, 2009.

8. Keshav BR, Zacharia G, Bhat VK, Joseph MK and Ideculla T: Laser therapy in diabetic macular edema. Oman Med J 23: 28-31, 2008.

9. Ashraf M, Souka AA and Singh RP: Central retinal vein occlusion: Modifying current treatment protocols. Eye (Lond) 30: 505-514, 2016

10. IpMS, ScottIU, VanVeldhuisen PC, Oden NL, Blodi BA, Fisher M, Singerman LJ, Tolentino M, Chan CK and Gonzalez VH; SCORE Study Research Group: A randomized trial comparing the efficacy and safety of intravitreal triamcinolone with observation to treat vision loss associated with macular edema secondary to central retinal vein occlusion: The Standard Care vs Corticosteroid for Retinal Vein Occlusion (SCORE) Study Report 5. Arch Ophthalmol 127: 1101-1114, 2009.

11. Haller JA, Bandello F, Belfort R Jr, Blumenkranz MS, Gillies M, Heier J, Loewenstein A, Yoon YH, Jiao J, Li XY, et al; Ozurdex GENEVA Study Group: Dexamethasone intravitreal implant in patients with macular edema related to branch or central retinal vein occlusion twelve-month study results. Ophthalmology 118: 2453-2460, 2011

12. Sellam A, Glacet-Bernard A, Coscas F and Souied EH: Abnormal retinal artery perfusion and optical coherence tomography angiography. J Fr Ophtalmol 40: 353-362, 2017 (In French).
13. Vogl WD, Waldstein SM, Gerendas BS, Schmidt-Erfurth U and Langs G: Predicting macular edema recurrence from spatiotemporal signatures in optical coherence tomography images. IEEE Trans Med Imaging 36: 1773-1783, 2017.

14. Puche N, Glacet A, Mimoun G, Zourdani A, Coscas G and Soubrane G: Intravitreal ranibizumab for macular oedema secondary to retinal vein occlusion: A retrospective study of 34 eyes. Acta Ophthalmol 90: 357-361, 2012.

15. Mete A, Saygili O, Mete A, Gungor K, Bayram M and Bekir N: Does ranibizumab (Lucentis ${ }^{\circledR}$ ) change retrobulbar blood flow in patients with neovascular age-related macular degeneration? Ophthalmic Res 47: 141-145, 2012.

16. Lucatto LFA, Magalhães-Junior O, Prazeres JMB, Ferreira AM, Oliveira RA, Moraes NS, Hirai FE and Maia M: Incidence of anterior segment neovascularization during intravitreal treatment for macular edema secondary to central retinal vein occlusion. Arq Bras Oftalmol 80: 97-103, 2017.

17. Ghasemi Falavarjani K, Iafe NA, Hubschman JP, Tsui I, Sadda SR and Sarraf D: Optical coherence tomography angiography analysis of the foveal avascular zone and macular vessel density after anti-VEGF therapy in eyes with diabetic macular edema and retinal vein occlusion. Invest Ophthalmol Vis Sci 58: 30-34, 2017.

18. Bitirgen G, Belviranli S, Malik RA, Kerimoglu H and Ozkagnici A: Effects of panretinal laser photocoagulation on the corneal nerve plexus and retinal nerve fiber layer in retinal vein occlusion. Eur J Ophthalmol 27: 591-595, 2017.

19. Pikkel YY, Sharabi-Nov A, Beiran I and Pikkel J: Comparison of anti-vascular endothelial growth factors, laser treatments and a combination of the both for treatment of central retinal vein occlusion. Int J Ophthalmol 9: 431-433, 2016.

20. Patel A, Nguyen C and Lu S: Central retinal vein occlusion: A review of current evidence-based treatment options. Middle East Afr J Ophthalmol 23: 44-48, 2016.

21. Yeh S, Kim SJ, Ho AC, Schoenberger SD, Bakri SJ, Ehlers JP, Thorne JE: Therapies for macular edema associated with central retinal vein occlusion: A report by the American Academy of Ophthalmology. Ophthalmology 122: 769-778, 2015.

22. Zhang L, Ke Y, Wang W, Shi X, Hei K and Li X: The efficacy of conbercept or ranibizumab intravitreal injection combined with laser therapy for Coats' disease. Graefes Arch Clin Exp Ophthalmol 256: 1339-1346, 2018.

23. Tadayoni R, Waldstein SM, Boscia F, Gerding H, Gekkieva M, Barnes E, Das Gupta A, Wenzel A and Pearce I; BRIGHTER Study Group: Sustained benefits of ranibizumab with or without laser in branch retinal vein occlusion: 24-month results of the BRIGHTER Study. Ophthalmology 124: 1778-1787, 2017.

24. Bertelmann T, Frank HU, Fuchs HA and Feltgen N: Branch retinal vein occlusion, macular ischemia, and intravitreal anti-VEGF therapy. Case Rep Ophthalmol 8: 271-278, 2017.

25. Ehlers JP, Kim SJ, Yeh S, Thorne JE, Mruthyunjaya P, Schoenberger SD and Bakri SJ: Therapies for macular edema associated with branch retinal vein occlusion: A report by the american academy of ophthalmology. Ophthalmology 124: 1412-1423, 2017.

26. Sakanishi Y, Usui-Ouchi A, Tamaki K, Mashimo K, Ito R and Ebihara N: Short-term outcomes in patients with branch retinal vein occlusion who received intravitreal aflibercept with or without intravitreal ranibizumab. Clin Ophthalmol 11: 829-834, 2017.

27. Chung CY and Li KKW: Optical coherence tomography angiography wide-field montage in branch retinal vein occlusion before and after anti-vascular endothelial-derived growth factor injection. Int Ophthalmol 38: 1305-1307, 2018.

This work is licensed under a Creative Commons Attribution-NonCommercial-NoDerivatives 4.0 International (CC BY-NC-ND 4.0) License. 